\title{
Natural-Repository Analogue Program
}

July 1-September 30,1981

Compiled by

David B. Curtis

This book wa prepgred as an account of work yponsored by an xaency of the United States Government.

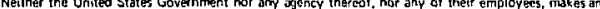
completeness, of usefulness of jry intormation, ippapotus, prosuct, or process dixloseo, of reoresents that its use would nol infringe wrivately owmed rights. Reference herein 10 any specilic commerciai product, process, of sevvica by trade name, trademats, manufaciurer, or otherwise, does not necessarily constitute or imply its endorsement, recommendation, of levoriory by the Unites

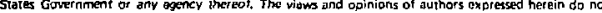




\title{
NATURAL REPOSITORY ANALOGUE PROGRAM \\ July 1--September 30,1981
}

\author{
Compiled by
}

David B. Curtis

\begin{abstract}
A report on the immobilization of uranium in the earth's crust has been completed. Techniques have been developed to do a comprehensive mass inventory of the $0 \mathrm{klo}$ reactor zones. These techniques were applied to a compilation of data from Oklo zones 2 and 3-4. The study shows large deficiencies of neodymium, ruthenium, and mass 99 elements ( ${ }^{99} \mathrm{Tc}$ or ${ }^{99} \mathrm{Ru}$ ) in the reactor zones. The extent of these deficiencies are correlated with the intensity of the nuclear reactions. Analyses of ores from the Key Lake uranium mineralization show that $60-70 \%$ of the radiogenic lead is missing from the ores.
\end{abstract}

I. PERSONNEL

This report covers some of the activities of the following individuals.

Los Alamos National Laboratory

T. M. Benjamin

E. A. Bryant

J. H. Cappis

D. B. Curtis

C. J. Duffy

W. D. Efurd

D. J. Frank

A. J. Gancarz

A. E. Norris

A. E. Ogard

D. J. Rokop 


\section{Idaho National Engineering Laboratory}

J. E. Delmore

A. L. Erickson

W. J. Maeck

R. A. Nielson

University of New Mexico

D. G. Brookins

\section{PROgRAM GBJECTIVE}

The Natural Repository Analogue program is a research effort to study the chemical processes and conditions that affect the retention and transport of elements in the earth's crust. The work of this program examines the stability of elements in the geologic record and their response to natural conditions over appropriately long periods of time.

Geologic burial is the favored method being considered for the disposal of commercially generated radioactive wastes. Appropriately chosen sites are thought to be relatively inert environments with respect to the stability of engineered waste containers. In addition, the geologic media itself will provide the ultimate containment, assuring that the wastes will remain isolated from the biosphere for adequate perioass of time. However, efforts to evaluate the effectiveness of the geologic environment in this regard are limited by our understanding of the effects of natural, physical, and chemical processes acting over periods of time much longer than that recorded by human experiences.

\section{PROGRESS REPORTED PREVIOUSLY}

Funding for the United States' participation in the international investigation of the $0 k l o$ natural fission reactor phenomenon began in fiscal year 1975. The first formal report of progress in this program was the annual report of fiscal year 1976 issued in November 1976. The Oklo phenomenon is the occurrence of self-sustaining fission chain reactions in a series of very rich uranium ore pockets located in a Precambrian pitchblende deposit in Gabon, Africa. The uranium formed critical masses $2 \times 10^{9}$ years ago. During criticality about $10^{4} \mathrm{~kg}$ of ${ }^{235} \mathrm{U}$ were fissioned. 
Early work in the program determined the inventory of elements produced and destroyed by the nuclear reactions. Comparisons between the abundances of nuclear products produced in the natural reactors and those measured in them today provided a quantitative measure of the loss of elements from these rocks in the two-billion years since the reactors were critical. Uranium, the principal nuclear fuel, appears to have been extremely stable during this time. Individual grains of uraninite have been mechanically intact since the nuclear reactions, and uranium isotopic ratios seem to mimic the spatial distribution of reactor operating characteristics with extremely high resolution. Despite the apparent stability of the minerals that contained the nuclear fuel, many of the nuclear products have been lost from their site of production and redistributed into the geologic surroundings. Of particular interest has been the loss of the long lived radioactive species ${ }^{99} \mathrm{Tc}$, its stable daughter ${ }^{99} \mathrm{Ru}$, and the other fission-produced ruthenium isotopes. These two elements were chemically fractionated during or within one-million years after the few hundred-thousandyear period of sustained nuclear reactions. The elements have moved updip in the ore bearing strata, with ${ }^{99}$ Tc moving at a faster rate than ruthenium.

To extend the study of element redistribution to a geologic setting different from $0 \mathrm{Klo}$, samples were collected at the urarium mineralization at key Lake in northern Saskatchewan, Canada. This ore body is situated at, and extends several hundred meters below, the unconformity between the Precambrian Athabasca sandstone and the underlying metasediments that compose the Wollaston Domain in the Canadian shield. This work shows extensive "equilibration" of the uranium-lead isotopic clock, $1.3 \times 10^{9}$ years ago. The overlying sandstone contains significant excesses of lead relative to uranium, indicating the chemical fractionation and redistribution of these two elements since that time.

\section{ACTIVITIES DURING THE REPORTING PERIOD}

The apparent stability of uranium, in the form of uraninite, at oklo stimulated a literature study of the immobilization of uranium in the crust of the earth. A report on the subject was completed during this quarter. The report concludes that uranium is primarily immobilized by the reduction of relatively oxidized uranium-bearing solutions and the subsequent formation of highly insoluble minerals of tetravalent uranium. At the high temperature of formation of hydrothermal uranium deposits, this can probably be considered an equilibrium process, reduction being achieved by complementary oxidation of 
ferrous iron in the minerals of the wall rock. However, at lower temperatures, such as those involved with the formation of roll-front uranium deposits, equilibrium may not be obtained. In such cases the concept of Eh is not applicable if the water contains redox couples that are not equilibrated. The reduction and subsequent fixation of uranium in a particular groundwater, then, depends not only on whether there are ions present that can reduce the oxidized species of uranium, but also on whether these ions will react with these species. The best candidate for a reductant of aqueous uranium is reduced sulfur.

An approach has been developed to calculate the abundance of elements produced and destroyed at $0 k 10$ by the nuclear reactions. Such methods are crucial in measuring the mass inventory of the reactor zones and, thus, characterizing the sources in these studies of element transport. The production and destruction of elements by nuclear reactions are dependent upon several reactor operating parameters; specifically, the time in the past when the reactors were critical, the duration of that criticality, the neutron fluence, and the neutron energy distribution. A series of differential equations have been written describing the production and destruction of particular nuclides by neutron capture, nuclear fission, and radioactive decay. The equations account for these processes throughout the entire neutron energy spectrum from thermal to fast neutrons. Solutions to the equations are used in conjunction with measured abundances of particular nuclides to calculate values for the operating parameters. Once these values have been determined they are used to calculate the quantity of nuclear products created in that rock by the reactions. $A$ description of these methods is included in a manuscript to be published in a forthcoming volume entitled Advances in the Science and Technology of the Management of High Level Nuclear Wastes.

The newly developed techniques were applied to a compilation of all available data regarding ${ }^{99} \mathrm{Tc}$ and ruthenium at the $0 \mathrm{k} 10$ reactors. The mass inventory of reactor zones 2 and 3-4 showed significant deficiencies of neodymium, ruthenium, and mass 99 elements ( ${ }^{99} \mathrm{Tc}$ or $\left.{ }^{99} \mathrm{Ru}\right)$. The proportional losses scaled with the intensity of the nuclear reactions; zone 2, which sustained an order of magnitude more nuclear reactions per gram of rock then zone 3-4, has lost significantly greater proportions of these three elements than the rocks from the less active zone 3-4. These results are discussed extensively in the previously mentioned manuscript. 
Analysis of samples from Key Lake show that 60-70\% of the radiogenic lead is missing from the ores. The quantities of deficient lead range from several hundred to tens of thousands of micrograms per gram of ore. The mass of lead missing from the ores represents a significant proportion of the leacin the immediately surrounding host rock. At this time a repository for this lead has not been unambiguously identified. The uranium-lead isotopic abundances have shown no systematic variations that will permit us to evaluate the time of formation of the ores or the times when uranium-lead fractionation occurred.

V. FUTURE ACTIVITIES

(A) Continue the study of uranium lead fractionation at Key Lake to determine the temporal aspects of the processes.

(B) Determine the spatial and temporal aspects of lead redistribution at oklo.

(C) Continue studies of ${ }^{99} \mathrm{Tc}$, ruthenium, and molybdenum redistribution at 0 klo reactor zone 9 .

(D) Continue development of techniques to do high precision isotopic analyses of barium in rocks from 0klo reactor zone 9 and its local host rocks. 